\title{
Do We Know the First Impressions We Make? Evidence for Idiographic Meta-Accuracy and Calibration of First Impressions
}

Social Psychological and

Personality Science

I(I) 94-98

(C) The Author(s) 2010

Reprints and permission: http://www. sagepub.com/journalsPermissions.nav DOI: 10.1 I77/1948550609356028 http://spps.sagepub.com

@SAGE

\author{
Erika N. Carlson', R. Michael Furr², and Simine Vazire'
}

\begin{abstract}
Can we trust our beliefs about the first impressions we make? The current article addresses this question by assessing "idiographic" meta-accuracy, or people's ability to detect how another person views their characteristic pattern of traits, and people's awareness of their level of meta-accuracy. Results from two samples suggest that people do achieve idiographic metaaccuracy (i.e., they know which traits a new acquaintance perceives as particularly characteristic of them) and that people's beliefs about the first impression they make are well calibrated (i.e., the people who are relatively more confident in the accuracy of their metaperceptions are in fact more accurate). Implications of idiographic meta-accuracy and the calibration of meta-accuracy are discussed, as are the ways in which future research can improve our understanding of the process of metaperception formation and the interpersonal consequences of meta-accuracy.
\end{abstract}

\section{Keywords}

interpersonal perception, personality, social cognition

Our first impressions of others are surprisingly accurate (Carney, Colvin, \& Hall, 2007; Fowler, Lilienfeld, \& Patrick, 2009; Levesque \& Kenny, 1993; Vazire \& Gosling, 2004), but do we know the first impressions we make? And perhaps more importantly, can we trust that our beliefs about the impressions we make, or our metaperceptions, are accurate? The current research addresses these questions by examining the accuracy of metaperceptions, called meta-accuracy, and by investigating whether people are aware of their level of meta-accuracy for a new acquaintance, or the "calibration" of meta-accuracy.

Metaperception research has broad theoretical implications for many domains of psychology such as the self (e.g., Leary, Haupt, Strausser, \& Chokel, 1998; Srivastava \& Beer, 2005), social cognition (e.g., Chambers, Epley, Savitsky, \& Windschitl, 2008), pathology (e.g., Christensen, Stein, \& Means-Christensen, 2003; Oltmanns, Gleason, Klonsky, \& Turkheimer, 2005), and interpersonal perception (Campbell $\&$ Fehr, 1990). For instance, research has revealed that the accuracy-or lack thereof - of metaperceptions has clear implications for successful self-presentation, smooth interpersonal functioning, and positive social outcomes (Anderson, Ames, \& Gosling, 2008; Cameron \& Vorauer, 2008; Elfenbein, Eisenkraft, \& Ding, 2009; Levesque, 1997; Oltmanns et al., 2005). Moreover, knowledge of how others perceive one's personality can also provide a path to improved self-knowledge (Vazire \& Carlson, 2009; Wilson \& Dunn, 2004).

Previous research on meta-accuracy has focused on whether people know who views them as particularly high or low on a trait (i.e., "dyadic" or "differential" meta-accuracy) or whether people know their reputation among a group (i.e., generalized meta-accuracy). For instance, in a typical study, a small group of new acquaintances takes part in a brief group discussion or in several one-on-one interactions with one another. Following the interactions, participants rate their impressions of each person, and they rate their metaperceptions of how each person viewed their personality (e.g., Malloy \& Janowski, 1992; Reno \& Kenny, 1992). This approach reveals, for example, whether Jason can identify which person in his group viewed him as particularly high or low on extraversion (i.e., dyadic meta-accuracy) and whether Jason knows how his group generally views him on extraversion (i.e., generalized meta-accuracy). Although most studies show that people know their general reputation on traits, results from such studies have been mixed with regard to dyadic or differential meta-accuracy (Carlson \& Furr, 2009; Kenny \& DePaulo, 1993). For instance, although most research from this trait-oriented tradition indicates that dyadic meta-accuracy for personality traits is weak for new acquaintances and for people within a single social

\footnotetext{
'Washington University in St. Louis, St. Louis, MO

${ }^{2}$ Wake Forest University, Winston-Salem, NC

Corresponding Author:

Erika N. Carlson, Washington University in St. Louis, Campus Box II25, St. Louis, MO 63130.

Email: encarlso@artsci.wustl.edu
} 
context (e.g., among one's college roommates; Levesque, 1997; Malloy \& Albright, 1990), recent research indicates that, when reflecting on the impressions they make on people from different social contexts, people are able to achieve significant differential meta-accuracy for traits (Carlson \& Furr, 2009).

One aim in this article is to complement this traditional traitoriented approach by taking a novel person-centered or idiographic approach to meta-accuracy, an approach that has received extensive attention in other domains of personality research (Bernieri, Zuckerman, Koestner, \& Rosenthal, 1994; Cronbach, 1955; Furr, Dougherty, Marsh, \& Mathias, 2007; Letzring, Wells, \& Funder, 2006). In the context of metaaccuracy, this approach examines whether people are able to detect which traits others perceive as relatively more or less characteristic of them. For instance, after meeting a new acquaintance, does Jason know that his new acquaintance sees him as relatively more outgoing than kind or as more fun-loving than conscientious? In other words, an idiographic approach will reveal whether a person can detect which traits others perceive as particularly characteristic of him or her, which is a different question than whether a person can detect which people view him or her as high or low on a given trait. Indeed, idiographic and trait-oriented approaches represent different and complementary perspectives on fundamental psychological phenomena (Furr, 2009; Pelham, 1993; Shoda, Mischel, \& Wright, 1994).

Furthermore, to our knowledge, research has not yet examined whether people are aware of their level of meta-accuracy, that is, whether people's confidence in the accuracy of their metaperceptions is well calibrated with their actual level of meta-accuracy. Calibration has received extensive attention in other domains (e.g., memory and learning), and such work has revealed several important consequences of calibration (Huff \& Nietfeld, 2009; Koriat, 2008; Koriat \& Bjork, 2005). We believe that calibration may also have important implications for understanding the processes and consequences involved in social perceptions such as metaperception.

Thus, a second aim of the current article is to extend the study of calibration to the domain of metaperception. We believe that examining calibration is a fundamental step in understanding metaperception formation and the consequences of meta-accuracy. Researchers have argued that in many ways metaperceptions guide social behavior and influence the course of relationships (Elfenbein et al., 2009; Levesque, 1997; Schlenker, 2003) and that "meta-accuracy can help us know which relationships to pursue and which to avoid" (Elfenbein et al., 2009, p. 1082). Although meta-accuracy is likely adaptive, we believe that meta-accuracy alone may not be enough for effective interpersonal functioning because poor calibration likely dampens the benefits of meta-accuracy. For example, someone who correctly believes she has made a good impression on her boss but is unsure about this may fail to capitalize on her accurate metaperception. Similarly, someone who correctly believes he has made a bad impression on a date but is unsure about this may waste time trying to confirm an already accurate metaperception. Such potentially important interpersonal phenomena merit empirical attention.

In sum, we believe that an idiographic approach to metaaccuracy and an examination of the calibration of meta-accuracy are important facets of interpersonal functioning and self-knowledge that have not yet been examined. In two samples, we provide a strong test of meta-accuracy and selfknowledge by examining whether people know how a new acquaintance perceives them and whether their confidence is calibrated with their level of meta-accuracy.

\section{Method \\ Participants}

Undergraduates from Wake Forest University (Sample 1: $N=$ 136, 68 males, 18 to 21 years old) and from Washington University in St. Louis (Sample 2: $N=124,62$ males, 18 to 23 years old) participated for course credit.

\section{Procedures and Measures}

Opposite-sex pairs of unacquainted participants engaged in 5min conversations, and actual impressions and metaperceptions were collected immediately after the interaction. ${ }^{1}$ In Sample 1, each participant was assigned the role of either judge or target: After the interaction, judges described their actual impressions of targets' personalities, and targets provided metaperceptions and confidence ratings. In Sample 2, participants served as both target and judge (i.e., after the interaction, both members described their actual impressions and provided metaperceptions and confidence ratings).

In both samples, impressions and metaperceptions were assessed in terms of the Big Five personality traits. In Sample 1, participants completed a 20-item questionnaire. Each trait was assessed with 4 items, and each item included a definition and an adjective describing the poles of the dimension (e.g., "Irritable: easily angered or made impatient was rated from 1 easygoing to 7 irritable"). In Sample 2, participants completed the 44-item Big Five Inventory (John, Naumann, \& Soto, 2008; John \& Srivastava, 1999) on a 7-point Likert-type scale (all alpha scale reliabilities from both samples $>.70$ ).

In Sample 1, targets rated confidence in their metaperceptions along a 7-point scale using the single item, "How accurate do you think you were in rating your partner's perception of your true personality?" In Sample 2, confidence was measured with two items: "How confident are you in your estimation of how your partner sees your personality?" and "How accurate was your estimation of how your partner sees your personality?" The average was computed $(\alpha=.75)$.

\section{Analyses \\ Meta-Accuracy}

Meta-accuracy was indexed in two ways. First, "overall metaaccuracy" was indexed as the Pearson correlation between a 
Social Psychological and Personality Science I(I)

target's metaperception profile and the judge's actual impression profile across all items (Furr, in press). ${ }^{2}$ Second, to control for potential normativeness biases or "stereotype accuracy" (i.e., inflated accuracy because of agreement about what the typical person is like), we computed conservative "distinctive meta-accuracy" (DMA) scores by removing the mean metaperception and the mean actual impression profiles from each metaperception profile and each actual impression profile, respectively, and correlating each target's "distinctive" metaperception profile with his or her judge's "distinctive" actual impression profile (Cronbach, 1955; Furr, 2008). Thus, DMA reflects the degree to which a person can detect the impression he or she makes, as unique from the impression the typical person is likely to make. Correlations were transformed using Fisher's $r$ to $z$ transformation for analyses then transformed back into correlations for presentation.

\section{Calibration}

In both samples, calibration was indexed as a regression slope with meta-accuracy correlations predicted from mean-centered confidence ratings. For Sample 1, the regression slope for calibration was assessed with standard regression, that is, with the individual as the unit of analysis. However, Sample 2 data were nonindependent (i.e., both members of the dyad served as a target and a judge). To account for nonindependence, we examined calibration at the level of the dyad as described by Kenny, Kashy, and Cook (2006). ${ }^{3}$ Specifically, using multilevel modeling, we predicted meta-accuracy scores from grand mean-centered confidence ratings, and we treated the intercept as a random effect and the slope as a fixed effect.

\section{Results}

In both samples, evidence of significant idiographic metaaccuracy emerged. Overall meta-accuracy was positive and significant, Sample $1 \bar{r}=.53, t(67)=17.57, p<.001$; Sample $2 \bar{r}=.38, t(123)=16.62, p<.001,{ }^{4}$ suggesting that target participants generally understood their partners' impressions of them. Importantly, evidence of meta-accuracy remained positive and significant, even when controlling for normativeness, Sample 1 DMA $\bar{r}=.14, t(67)=4.19, p<.001$; Sample 2 DMA $\bar{r}=.14, t(123)=5.25, p<.001$. These results suggest that participants generally understood the unique impression they made on their partner, as different from the impression the typical person is likely to make.

Both samples also provided evidence of significant calibration. Specifically, calibration was positive and significant in both samples for overall meta-accuracy, Sample $1 \beta=.34$, $t(66)=2.91, p<.01$; Sample $2 \beta=.15, t(121)=1.73, p<$ .05 , and remained significant for the more conservative DMA meta-accuracy index, Sample $1 \beta=.29, t(66)=2.49, p<$ .01 ; Sample $2 \beta=.17, t(121)=1.90, p<.05$. These results suggest that participants were aware of their relative level of meta-accuracy, or when their metaperceptions were likely to be accurate or inaccurate. In other words, the people who were relatively more accurate in estimating the impression they made were also more confident in their estimation, and the people who were relatively less accurate were also less confident.

\section{Discussion}

After a brief conversation, people can detect which traits a new acquaintance views as particularly characteristic of them. In addition, people have insight into their level of metaaccuracy; that is, the people who are relatively more confident in the accuracy of their metaperceptions are in fact more accurate. Although much of the literature paints a grim picture of people's social acuity, suggesting that people are often inaccurate (Ames \& Kammrath, 2004; DePaulo, Charlton, Cooper, Lindsay, \& Muhlenbruck, 1997; Kenny \& DePaulo, 1993; Swann \& Gill, 1997), our findings suggest that people understand the impression they make after a short conversation, and they can recognize when they are likely to be mistaken. In fact, unlike other types of social perception (e.g., deception; DePaulo et al., 1997), our results suggest that people can trust their perceptions when reflecting on a social interaction. Combined with recent research demonstrating that people achieve significant "differential" meta-accuracy (Carlson \& Furr, 2009), the current idiographic results begin painting a broadly positive picture of people's social acuity. That is, it is impressive that people could even achieve meta-accuracy after such limited contact with a new acquaintance but even more impressive that they were aware of their level of meta-accuracy.

Unlike the designs employed in many meta-accuracy studies, our design was purely dyadic; that is, each target interacted with a single (and different) judge. Building on the current findings, future research examining our novel idiographic approach to meta-accuracy using the traditional round-robin design (i.e., each member of a small group rates and is rated by all other members), and designs that include multiple judges may reveal many additional interesting facets of both metaaccuracy and calibration. For instance, this approach would provide a generalized idiographic meta-accuracy score (i.e., do people know the way their characteristic pattern of traits are generally viewed by others?), differential idiographic metaaccuracy scores (i.e., can people detect the unique way each person views their pattern of traits?), and differential calibration scores (i.e., can people detect which person they are relatively more accurate about?). Furthermore, we hope that future research will explore person-specific factors and observable cues that influence meta-accuracy and calibration. For example, this line of research might identify whether there are "good metaperceivers" who are especially perceptive about the impressions they make or "good partners" who are especially expressive about the impression they have formed.

Our findings may also have important theoretical implications for understanding how metaperceptions are formed. One strong conclusion in the literature is that people simply assume that others see them as they see themselves (Kenny \& DePaulo, 1993), yet researchers have never explicitly tested this conclusion. We believe that one avenue for investigating this issue is 
by assessing people's confidence in their metaperceptions. It is possible that, instead of confidently assuming that others view them as they view themselves, people fall back on their selfperception as their metaperception only under conditions of low certainty. However, it may also be the case that when people feel that they have brought a new acquaintance to view them as they view themselves, they are particularly confident in the accuracy of their metaperceptions. Future research assessing confidence in metaperceptions may shed light on when people do and do not assume others share their selfperceptions. For example, assessing confidence in metaperceptions for various types of traits may reveal that people assume others view them as they view themselves on observable traits (Vazire, in press); likewise, assessing confidence in metaperceptions for people from specific social contexts may reveal that people assume certain types of people (e.g., close others) view them as they view themselves. We believe that future research examining these moderators of calibration (e.g., kinds of people or types of traits) will provide important insight into the processes underlying metaperception formation.

Finally, although meta-accuracy is important to interpersonal functioning (Anderson et al., 2008; Elfenbein et al., 2009; Levesque, 1997; Oltmanns et al., 2005), we suspect that calibration of meta-accuracy is also crucial for interpersonal functioning and hope that future research will explore the interpersonal consequences of calibration, such as examining how others react to a well-calibrated "metaperceiver" (e.g., Tenney, MacCoun, Spellman, \& Hastie, 2007).

\section{Notes}

1. Before and after the interaction, participants also completed questionnaires unrelated to the current study. The interactions were videotaped with participants' knowledge.

2. We also conducted analyses based on profiles of trait scores. Results were highly similar to those based on profiles of itemlevel responses, as reported in the text.

3. The partner path was not significant and was excluded from the model. Gender did not distinguish dyad members, so dyads were considered indistinguishable.

4. The $p$ values are one-tailed.

\section{Declaration of Conflict of Interest}

The authors declared that they had no conflicts of interests with respect to their authorship or the publication of this article.

\section{Financial Disclosure/Funding}

The authors declared that they received no financial support for their research and/or authorship of this article.

\section{References}

Ames, D. R., \& Kammrath, L. K. (2004). Mind-reading and metacognition: Narcissism, not actual competence, predicts self-estimated ability. Journal of Nonverbal Behavior, 28, 187-209.

Anderson, C., Ames, D. R., \& Gosling, S. D. (2008). Punishing hubris: The perils of overestimating one's status in a group. Personality and Social Psychology Bulletin, 34, 90-101.
Bernieri, F., Zuckerman, M., Koestner, R., \& Rosenthal, R. (1994). Measuring person perception accuracy: Another look at selfother agreement. Personality and Social Psychology Bulletin, 20, 367-378.

Cameron, J. J., \& Vorauer, J. D. (2008). Feeling transparent: On metaperceptions and miscommunications. Social and Personality Psychology Compass, 2, 1093-1108.

Campbell, J. D., \& Fehr, B. (1990). Self-esteem and perceptions of conveyed impressions: Is negativity associated with greater realism? Journal of Personality and Social Psychology, 58, 122-133.

Carlson, E. N., \& Furr, R. M. (2009). Evidence of differential metaaccuracy: People understand the different impressions they make. Psychological Science, 20, 1033-1039.

Carney, D. R., Colvin, C. R., \& Hall, J. A. (2007). A thin slice perspective on the accuracy of first impressions. Journal of Research in Personality, 41, 1054-1072.

Chambers, J. R., Epley, N., Savitsky, K., \& Windschitl, P. D. (2008). Knowing too much: Using private knowledge to predict how one is viewed by others. Psychological Science, 19, 542-548.

Christensen, P. N., Stein, M. B., \& Means-Christensen, A. (2003). Social anxiety and interpersonal perception: A social relations model analysis. Behaviour Research and Therapy, 41, 1355-1371.

Cronbach, L. J. (1955). Processes affecting scores on "understanding of others" and "assumed similarity." Psychological Bulletin, 52, 177-193.

DePaulo, B. M., Charlton, K., Cooper, H., Lindsay, J. J., \& Muhlenbruck, L. (1997). The accuracy-confidence correlation in the detection of deception. Personality and Social Psychology Review, 1, 346-357.

Elfenbein, H. A., Eisenkraft, N., \& Ding, W. W. (2009). Do we know who values us? Dyadic meta-accuracy in the perception of professional relationships. Psychological Science, 20, 1081-1083.

Fowler, K. A., Lilienfeld, S. O., \& Patrick, C. J. (2009). Detecting psychopathy from thin slices of behavior. Psychological Assessment, 21, 68-78.

Furr, R. M. (2008). A framework for profile similarity: Integrating similarity, normativeness, and distinctiveness. Journal of Personality, 76, 1267-1316.

Furr, R. M. (2009). Profile analysis in person-situation integration. Journal of Research in Personality, 43, 196-207.

Furr, R. M., Dougherty, D. M., Marsh, D. M., \& Mathias, C. W. (2007). Personality judgment and personality pathology: Selfother agreement in adolescents with conduct disorder. Journal of Personality, 75, 629-662.

Huff, J. D., \& Nietfeld, J. (2009). Using strategy instruction and confidence judgments to improve metacognitive monitoring. Metacognition and Learning, 4, 161-176.

John, O. P., Naumann, L. P., \& Soto, C. J. (2008). Paradigm shift to the integrative big-five trait taxonomy: History, measurement, and conceptual issues. In O. P. John, R. W. Robins, \& L. A. Pervin (Eds.), Handbook of personality: Theory and research (pp. 114-158). New York, NY: Guilford Press.

John, O. P., \& Srivastava, S. (1999). The Big Five trait taxonomy: History, measurement, and theoretical perspectives. In L. A. Pervin \& O. P. John (Eds.), Handbook of personality: Theory and research (2nd ed., pp. 102-138). New York: Guilford. 
Kenny, D. A., \& DePaulo, B. M. (1993). Do people know how others view them? An empirical and theoretical account. Psychological Bulletin, 114, 145-161.

Kenny, D. A., Kashy, D., \& Cook, W. (2006). Dyadic data analysis. New York: Guilford.

Koriat, A. (2008). Subjective confidence in one's answers: The consensuality principle. Journal of Experimental Psychology: Learning, Memory, and Cognition, 34, 945-959.

Koriat, A., \& Bjork, R. A. (2005). Illusions of competence in monitoring one's knowledge during study. Journal of Experimental Psychology: Learning, Memory, and Cognition, 31, 187-194.

Leary, M. R., Haupt, A. L., Strausser, K. S., \& Chokel, J. T. (1998). Calibrating the sociometer: The relationship between interpersonal appraisals and the state self-esteem. Journal of Personality and Social Psychology, 74, 1290-1299.

Letzring, T. D., Wells, S. M., \& Funder, D. C. (2006). Information quantity and quality affect the realistic accuracy of personality judgment. Journal of Personality and Social Psychology, 91, 111-123.

Levesque, M. J. (1997). Meta-accuracy among acquainted individuals: A social relations analysis of interpersonal perception and metaperception. Journal of Personality and Social Psychology, 72, 66-74.

Levesque, M. J., \& Kenny, D. A. (1993). Accuracy of behavioral predictions at zero-acquaintance: A social relations analysis. Journal of Personality and Social Psychology, 65, 1178-1187.

Malloy, T. E., \& Albright, L. (1990). Interpersonal perception in a social context. Journal of Personality and Social Psychology, 58, 419-428.

Malloy, T. E., \& Janowski, C. L. (1992). Perceptions and metaperceptions of leadership: Components, accuracy, and dispositional correlates. Personality and Social Psychology Bulletin, 18, 700-708.

Pelham, B. W. (1993). The idiographic nature of human personality: Examples of the idiographic self-concept. Journal of Personality and Social Psychology, 64, 665-677.

Oltmanns, T. F., Gleason, M. E., Klonsky, E. D., \& Turkheimer, E. (2005). Metaperception for pathological personality traits: Do we know when others think that we are difficult? Consciousness and Cognition, 14, 739-751.

Reno, R. R., \& Kenny, D. A. (1992). Effects of self-consciousness and social anxiety on self-disclosure among unacquainted individuals: An application of the social relations model. Journal of Personality, 60, 79-94.
Schlenker, B. R. (2003). Self-presentation. In M. R. Leary \& J. P. Tangney (Eds.), Handbook of self and identity (pp. 492-518). New York: Guilford.

Shoda, Y., Mischel, W., \& Wright, J. C. (1994). Intra-individual stability in the organization and patterning of behavior: Incorporating psychological situations into the idiographic analysis of personality. Journal of Personality and Social Psychology, 67, 674-687.

Srivastava, S., \& Beer, J. S. (2005). How self-evaluations relate to being liked by others: Integrating sociometer and attachment perspectives. Journal of Personality and Social Psychology, 89, 966-977.

Swann, W. B. Jr., \& Gill, M. J. (1997). Confidence and accuracy in person perception: Do we know what we think we know about our relationship partners? Journal of Personality and Social Psychology, 73, 747-757.

Tenney, E. R., MacCoun, R. J., Spellman, B. A., \& Hastie, R. (2007). Calibration trumps confidence as a basis for witness credibility. Psychological Science, 18, 46-50.

Vazire, S. (in press). Who knows what about a person? The self-other knowledge asymmetry (SOKA) model. Journal of Personality and Social Psychology.

Vazire, S., \& Carlson, E. N. (2009). Personality and self-knowledge: Do people know themselves? Manuscript submitted for publication.

Vazire, S., \& Gosling, S. D. (2004). ePerceptions: Personality impressions based on personal websites. Journal of Personality and Social Psychology, 87, 123-132.

Wilson, T. D., \& Dunn, E. W. (2004). Self-knowledge: Its limits, value, and potential for improvement. Annual Review of Psychology, 55, 493-518.

\section{Bios}

Erika N. Carlson is a graduate student in the Psychology Department at Washington University in St. Louis.

R. Michael Furr is an Associate Professor and McCulloch Fellow in the Psychology Department at Wake Forest University.

Simine Vazire is an Assistant Professor and Director of the Personality and Self-Knowledge Lab in the Psychology Department at Washington University in St. Louis. 